\title{
Cultural Landscapes and Botanic Gardens: the case of Mon - Repos Garden in Corfu island, Greece
}

\author{
Alexandra - Aikaterini Andrianou, Georgios Papaioannou \\ Ionian University, Greece, alexandra6891@gmail.com, Ionian University, Greece, gpapaioa@ionio.gr
}

\section{Keywords}

Mon-Repos

Heritage tourism; Botanic

Garden; Sustainability and

Prosperity of the Garden

\begin{abstract}
Cultural landscapes play an essential role in preservation and enhancement of cultural heritage assets promoting the sustainable tourism prospect. The paper explores the development of cultural landscapes and the role they can play in preservation, management and promotion of historic areas which have the ability of playing an active role in social life, triggering and awaking social and environmental values. The overall objective is to present how the development of Mon Repos, a historical and environmental landmark which is located in Corfu Island, can become a Botanic Garden (BGCI network) towards sustainability concept. More specifically the paper presents:

-The importance of culture combined culture as an agent combined with historic and nature assets having as a result a distinctive cultural landscape

-Proposes the establishment of Mon-Repos Botanic Garden through recommendations on strategic management plan

-Presents how cultural and environmental issues add prospects on innovation potential in tourism value chain

The authenticity of the paper relies on the development of Mon- Repos site through a holistic approach taking into account the principles of sustainability, cultural tourism enhancement as well as historic and cultural values.
\end{abstract}

\section{Introduction}

Cultural landscapes play an essential role in preservation and enhancement of cultural heritage assents, promoting the sustainable tourism prospect. The National Trust for Historic Preservation defines heritage tourism as travelling to experience places, artifacts and activities as authentically presents stories and people of past and present. Moreover, the definition includes the visitation to cultural, historic and natural resources in order to research and plan next issue points concerning the recognition of local or regional points of interest and their development in order to maximize visitation (Gibson, 2015). Consequently, the development of cultural landscapes and their promotion most of the times relies on local authorities decisions and most of the times local community's participation and involvement on these processes exist to a certain extent (Waterton and Watson, 2013).

In addition to this, local and international tourism prospect increases growth in order to follow new needs in tourism value needs and the creation, development and promotion of natural, cultural places is in center stage of Europe 2020 regional planning agenda (Europe, 2020).

In this paper, the term cultural landscape is used to present distinctive places of interest which combine natural and cultural assets, more specifically botanic gardens. The term of cultural landscape is a term which is used in general for landscapes despite the fact that most landscapes which have in some degree by human use or representation considered as cultural (Selman, 2004). Additionally, the development of these cultural landscapes contributes to regional and local identity.

International organizations have recognized the universal value of botanic gardens in many levels. Botanical Gardens Conservation International (BGCI) as also as the United Nations Educational, Scientific and Cultural Organization 
(Unesco) have drive forward and support places of cultural and environmental value providing guidelines and tools towards sustainable development, promotion and prosperity of botanic gardens in general. Taking care and giving prominence in such places contributes to social well-being; add prospects in cultural, natural, tourism value chain through a sustainable development model (Manrique et al., 2016).

This paper deals with the establishment of Botanic Garden of Mon - Repos in Corfu Island, in Greece. It is a garden which has been designed and used for more than 185 years. The most important fact though is that the area in which Mon - Repos garden is located, consists of an area of numerous historical, archeological and cultural features.

\section{Aims and objectives}

This paper aims to understand and present the establishment and development of Mon - Repos Botanic Garden in Corfu Island, through sustainability, preservation and promotion aspect. In addition, the paper searches the connection between areas, cultural heritage assets and sustainable tourism prospect as well.

The paper raises 3 basic questions:

-How historic areas contribute to environmental planning sector?

-In what way old and new uses of an existing historical and environmental site can become pillar of future prospects in the local tourism value chain?

-What kind of actions should be implemented by local factors towards future development and prosperity of MonRepos site?

Overall, the paper proposes the conversion of Mon- Repos site in a Botanic Garden using a holistic approach researching sustainability's principles, local participation and sustainable tourism prospect as well.

\section{Methodology}

After a literature review on botanic gardens and a brief presentation of Mon- Repos estate, we produced a proposal concerning the establishment Mon-Repos Botanic Garden. For this purpose, we advised the BGCI Network and guidelines in order to define the characteristics of the botanic garden. Towards the same end, fieldwork was developed in order to observe and record the existing situation of the landmark. Our discussion and results are based on authors' personal experience from research processes and experiences from the last decade.

\section{The cultural landscape of Kanoni's suburban area}

\subsection{The ancient city and today's cultural, environmental profile}

The suburban area of Kanoni in Corfu Island located in south side of the city, founded by the Corinthian settlers in the $8 \mathrm{BC}$, considered as one the most featured heritage tourism destinations. The ancient city developed and flourished between two natural harbors and managed to become a leader in naval and commercial sector. Moreover, it preserved at the same location through Classical, Hellenistic, Roman and Early Christian periods (Baika, 2014). Today, the area also Known as Kanoni peninsula, considered as a sub-urban area of today's city. The area consists of a typical example of a modern area over an ancient one. Additionally, archaeological and environmental features are blended together, creating a cultural landscape of cultural, environmental and human characteristics of past and present (Jacques, 1995; Knapp and Ashmore, 1999), demonstrated by the existence of archeological and natural features.

As tourism hot spot of Corfu it has built a tourism profile which is closely related to heritage tourism definition, however though the history and significance of numerous important sites have not evaluated and promoted yet.

One example which will support the above issue point is our case study concerning the establishment of Mon-Repos Botanic Garden.

\section{Brief history of Mon - Repos estate}

\subsection{The construction of the Mon - Repos estate}

The estate, the mansion and the garden, was constructed from 1821 until 1832. Until today it is not clear who was the architect who designed the project. The owner of the estate was Sir Frederic Adam, second British high commissioner of Ionian Islands. His first arrival in Corfu Island was in 1818, when he met and got married to an upper class named Nina Palatianou, in 1820. Until 1831 the mansion and the garden was completed, creating outstanding scenery of 12 hectares.

Furthermore, garden's design followed the 19th century English Regency Style, a prototype characterized by classical design and romance features. In addition to the above, the location of the estate has not been chosen randomly. 
Ancient Greek trends and influences in Regency Style combined to the archeological remains of Kardaki's temple made project's ideal location spot.

As we mentioned above, the garden followed the English model plant design but due to the lack of irrigation system, representative Mediterranean plants was chosen and installed. Garden's plant diversity was demonstrated by the existence of deciduous evergreen trees and shrubs and exotic palm trees as well (Zernioti, 2002). The plant diversity has certainly changed over years but archival resources from General State Archives -Corfu's department- may provide useful documents concerning the plant diversity of the garden.

In 1864, after the accession of the United States of the Ionian Islands in Greece the council provided the mansion and a part of the garden, 11,8 hectares to the dynasty of George A' who named it Mon-Repos (my rest), in order to use it as a summer residence. Since that it was used by the royal family until 1967.

Additionally, the rest 12 hectares was given to Hellenic State and in 1994 the development of the garden transferred to Municipality of Corfu by law.

Mon- Repos estate remained closed for the public from 1974 until 1992, due to legal matters with the royal family. In 1992 Municipality of Corfu managed to prove Mon -Repos legal ownership, providing access to general public.

Finally, it is worth noting that Mon- Repos mansion it has been granted by Municipality of Corfu to Ministry of Culture, which led to the restoration and enhancement of the mansion in order to become today, Palaiopoli's Museum

\subsection{The garden today}

Mon- Repos garden is located $3 \mathrm{~km}$ from away the Old Town of Corfu, lying today above the ancient city that's why it is named Palaiopolis area. The garden's area covers a scale of 25 hectares, combining an interesting mixture of lush vegetation (Figure 1, Figure 2, Figure 3). Furthermore, the existence of pathways combined to resting and viewing areas makes the place friendlier to visitors. Mon-Repos garden has also increased cultural value due to the Palaiopolis Museum operation. The main pathway leads visitors to the main residence, which is a small palace with spectacular view.

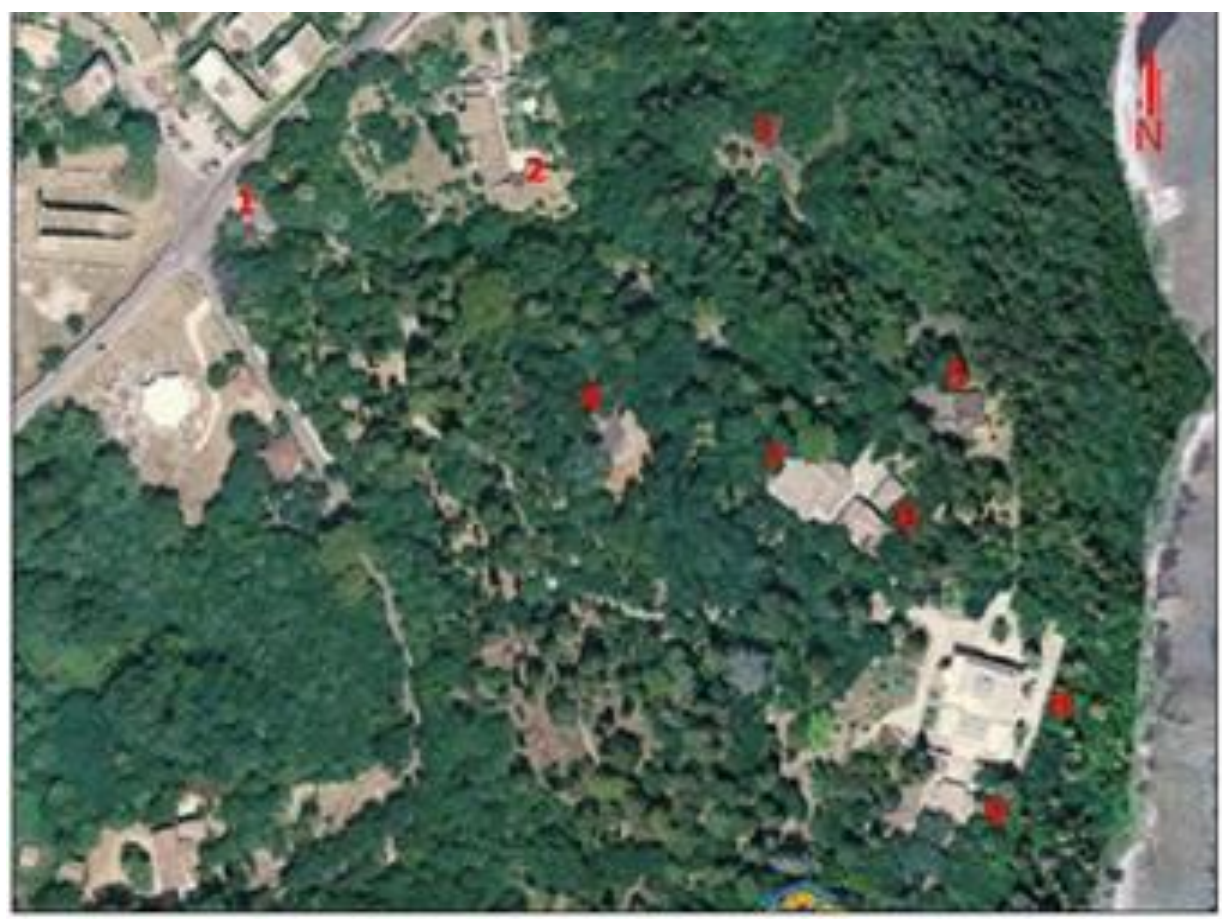

Figure 1 - Several interesting points in Mon-Repos estate, source: The background of the map was provided from the Hellenic Cadastre \& Mapping Agency S.A 


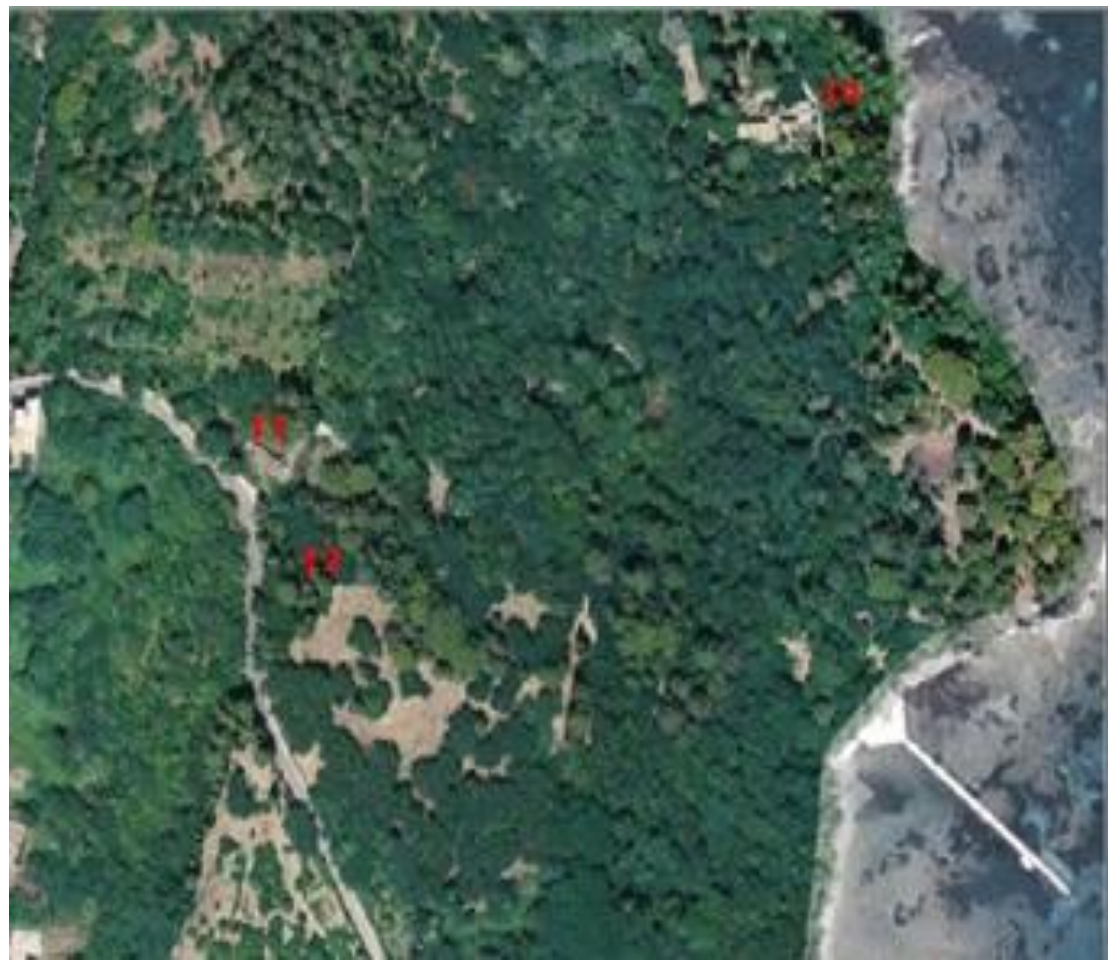

Figure 2 - Several interesting points in Mon-Repos estate, source: The background of the map was provided from the Hellenic Cadastre \& Mapping Agency S.A

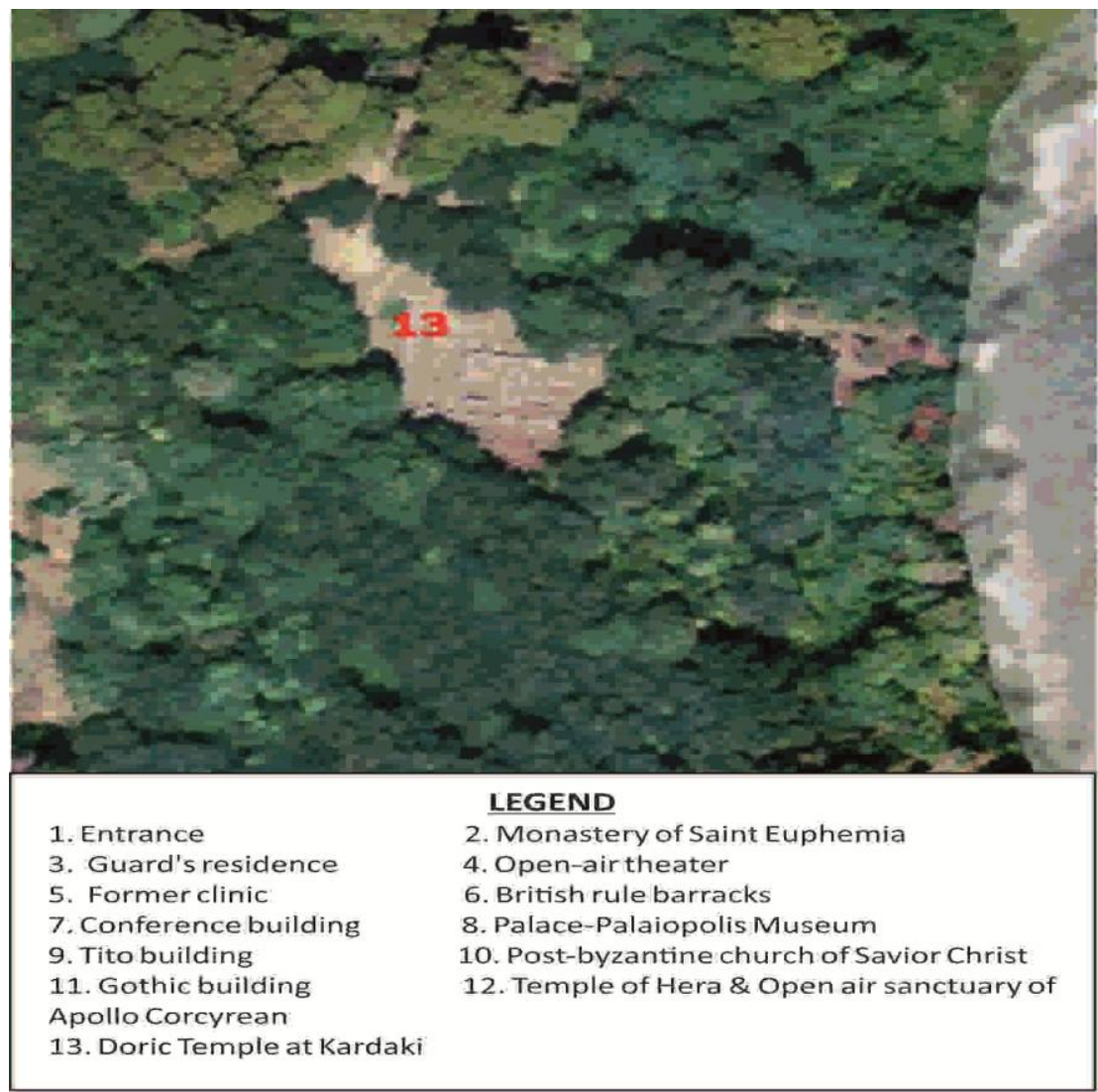

Figure 3 - Several interesting points in Mon-Repos estate, source: The background of the map was provided from the Hellenic Cadastre \& Mapping Agency S.A

At Mon-Repos estate there are also other buildings which have been constructed in different time periods and some of them are well preserved and other not. They exist ten buildings: Mon - Repos palace, the monastery of Saint Euphemia, guard's residence, guardhouse, former clinic, conference building, British rule barracks, Tito building, post-byzantine church of Savior Christ, gothic building. The main building which hosts Palaiopolis Museum well 
Alexandra-Aikaterini Andrianou, Georgios Papaioannou/ The Academic Research Community Publication

preserved but the other nine buildings, with the exception of the conference building, need to be restored. Some of them are presented below:

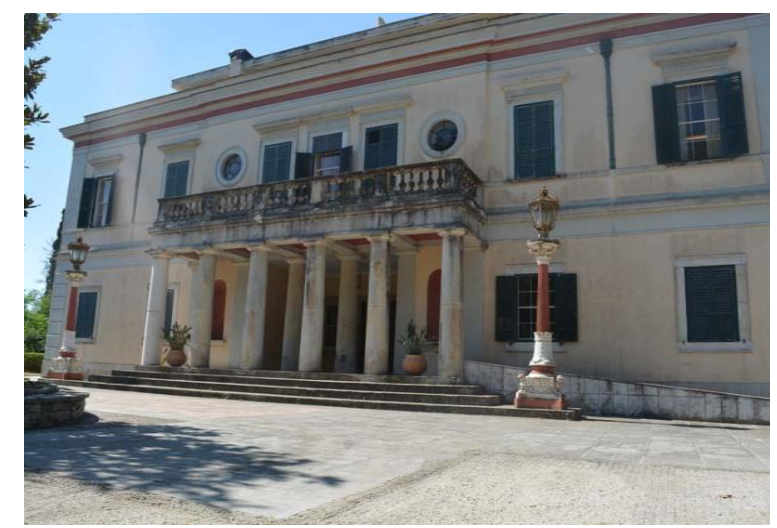

Figure 4 - Mon-Repos Palace, Palaiopolis Museum, photo: Alexandra - Aikaterini Andrianou, April 2017

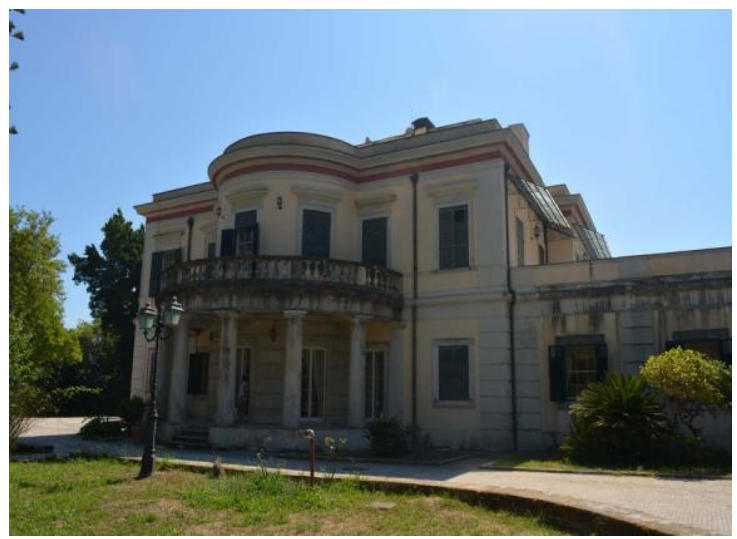

Figure 5 - Mon- Repos Palace, Palaiopolis Museum, photo: Alexandra - Aikaterini Andrianou, April 2017

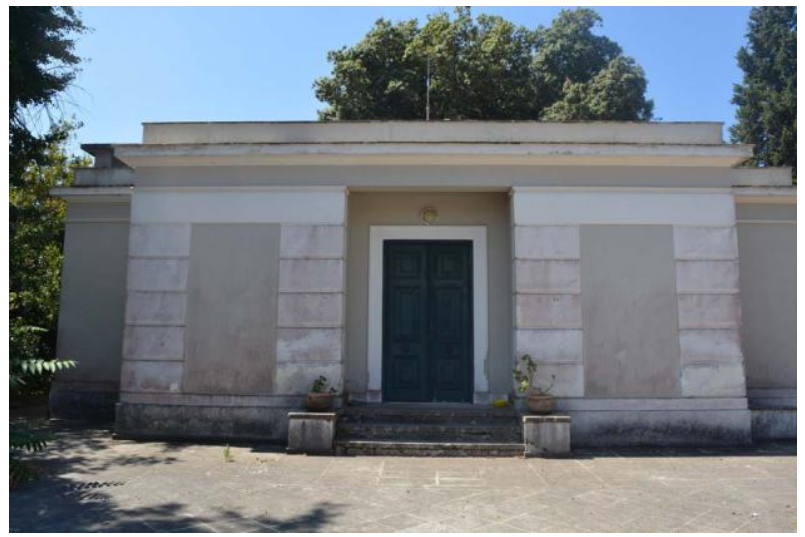

Figure 6 - Tito building, photo: Alexandra - Aikaterini Andrianou, April 2017

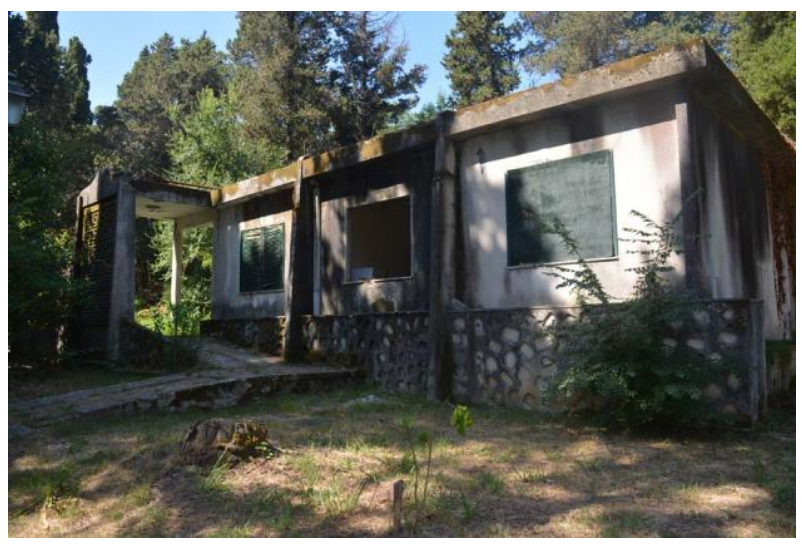

Figure 7 - Former clinic building, photo: Alexandra - Aikaterini Andrianou, April 2017 


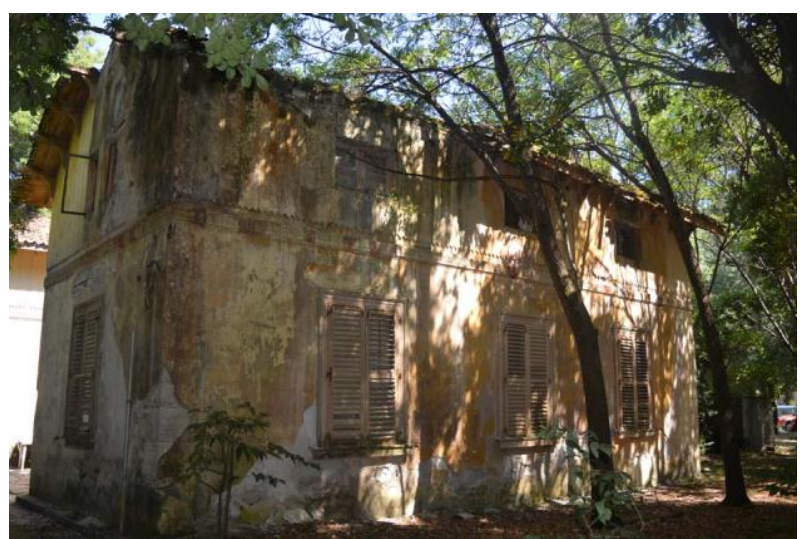

Figure 8 - British rule barracks building, photo: Alexandra - Aikaterini Andrianou, April 2017

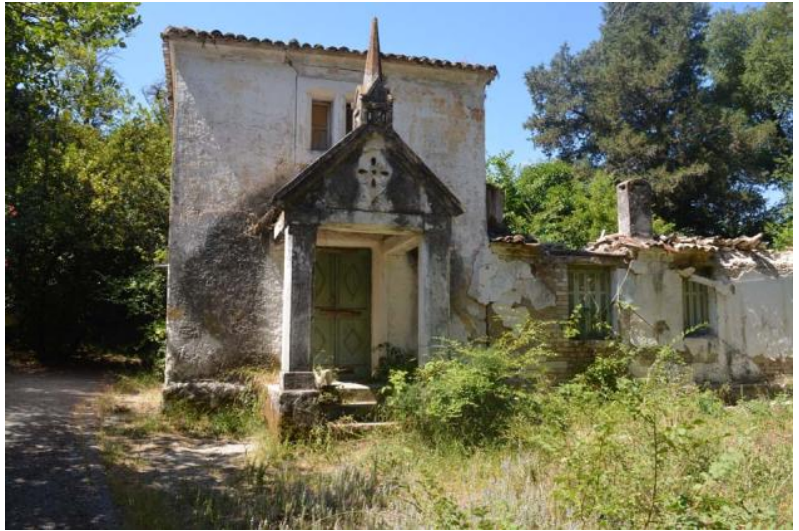

Figure 9 - Gothic building, photo: Alexandra - Aikaterini Andrianou, April 2017

Especially, the British rule barracks, gothic and former clinic are facing serious structural damages, creating a disappointing overall view of the landmark.

Moreover, the archeological remains which are located at the site increase the cultural value of the place, boosting attractiveness and archeological interest. The temple of Hera, the open air sanctuary of Apollo Corcyrean (Figure 10) as also as the Doric temple of Kardaki (Figure 11), all located at the south side of the estate. Visitors, in order to reach them should walk through minor pathways. It is important to mention that every archeological site has its explanatory sign, presenting archeological evidence and photos from the excavation process. Resting areas are included close to those sites and visitors can take a break and enjoy the spectacular view.

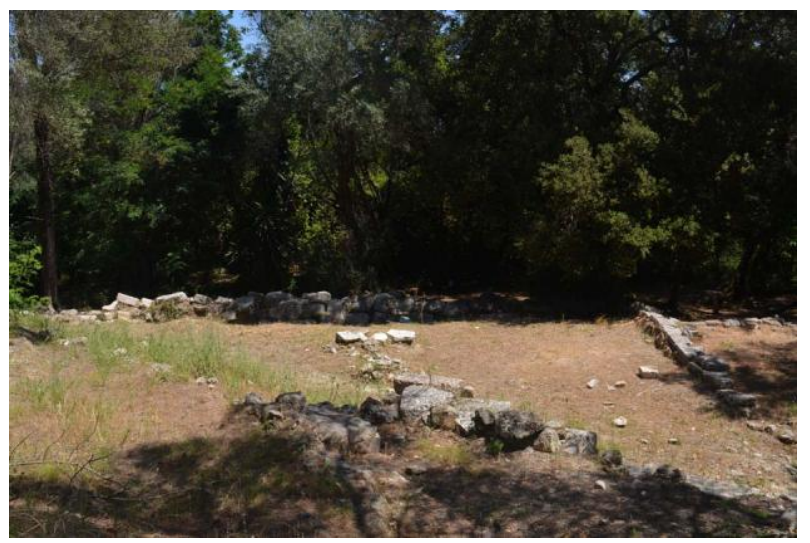

Figure 10 - Archeological Site of Heraion and open air sanctuary of Apollo Corcyrean, photo: Alexandra - Aikaterini Andrianou, April 2017 


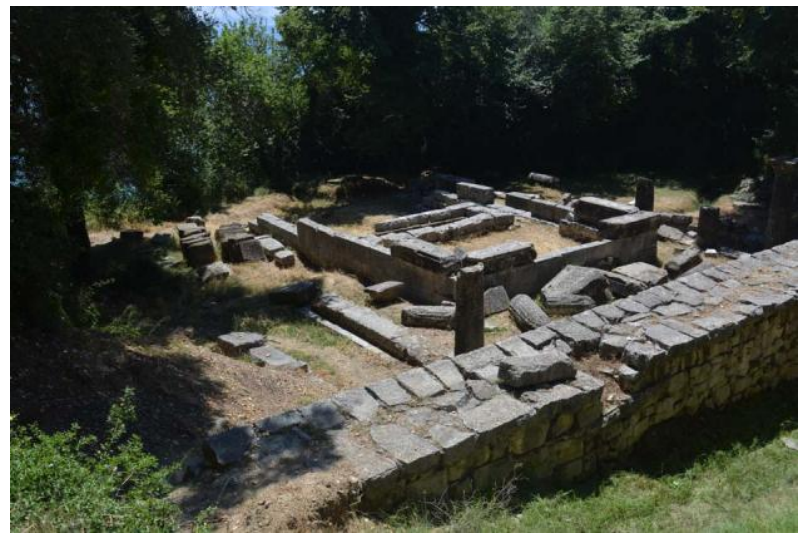

Figure 11 - Doric Temple at Kardaki, photo: Alexandra - Aikaterini Andrianou, April 2017

Furthermore, and from the fieldwork process it is worth to mention that resting and also viewing areas are multiple in the estate clustering around cultural and natural points. They are located mostly in shady areas in order to protect visitors especially in the summer season. The main problem though is their location. As we observed these green and comfortable areas exist in open spaces along by minor pathways. These pathways are not accessible to all, especially to visitors with special needs, a reality which raises questions towards accessibility to green spaces for all (Jiang et al., 2015).

On the other hand, we were surprised by the operation of Pinto, therapeutic riding association which is located south of the estate.

The garden also hosts an open air theater, established and operated by the Municipality of Corfu. Especially, in summer season multiple cultural events take place there (theatrical performances and concerts) and Mon-Repos open air theater considered as one of the most well known meeting points. During this summer the open air theater is not operating, due to construction works in order to restore it.

\section{Towards the establishment of Mon-Repos Botanic Garden}

\subsection{Following guidelines, the International Agenda of BGCI}

The last 28 years is has been made huge progress concerning the global loss of plant diversity. The establishment of botanical gardens internationally is helping at plant conservation sector. Botanic gardens contribute towards this aspect in many ways; by protecting plants facing threat, dealing with in situ and ex situ conservation processes, educating and informing visitors and general public towards sustainability issues. Botanic Gardens Conservation International (BGCI) was established in 1987 under the auspices of International Union for the Conservation of Nature (IUCN). In 1989, the global voice for all botanic gardens, publishes the Botanic Gardens Conservation Strategy. Subsequently, this document followed extensive review by policy makers and researchers and an improved document; the International Agenda for Botanic Gardens was published by the BGCI in 2000. Ten years later, BGCI following environmental and social needs evaluated botanic gardens policy document, considered important to upgrade it and publishes a new edition for the botanic garden community. In this way the second edition of this policy document considered to be one of the most noteworthy and useful tool, trying to reach and present a global framework for the development of botanic gardens. Under this perspective the basic goals which underlies BGCI and they should be taken into account by local authorities and stakeholders for the establishment and development of every botanic garden are summarized below (BGCI, 2012):

- Raising public awareness concerning plant diversity, stimulating the interest of plant diversity's value and future threats as well

-Giving solutions and taking actions concerning the improvement of natural environment, playing a part in local, regional and sub-regional level

-Improving social well-being evolving local communities and institutional participation in botanic garden programs, highlighting the sustainable use of plants

-Promoting the Education for Sustainable Development (ESD) model in order to develop public awareness programs in botanic gardens, contributing in environmental planning sector

Furthermore, BGCI has worked on a technical manual of planning concerning botanic gardens development and management process (Gratzfeld, 2016) which we use as a guideline in order to present our proposal of Mon-Repos Botanic Garden. 


\subsection{Conditions and Objectives}

In order to understand the establishment of Mon - Repos Botanic Garden process, it is important to point out the conditions and objectives which will lead us to SWOT analysis process.

Mon - Repos Botanic Garden should include two main roles. A project schedule should be defined early which will deal with two development stages, firstly the protection preservation of plant material, and at the same time to raise public awareness towards gardens historical value and sustainability context. The conditions and objectives are presented below:

As regards conservation and protection of plant material:

-Development of structure facilities using the unused buildings of the estate. The use of these buildings will host offices, herbarium and a seed bank as well.

-Another high priority is the development of a scientific plant database in which botanic information about plant species will be recorded

-Monitoring of all plants throughout the year and wild species too

-It is essential to mark (explanatory signs) all plant species

-Participating in seed exchanges with other botanical gardens

As concerns Mon - Repos social image:

-Accessible to everyone

-Exchanging know-how and scientific results with other botanic gardens especially in Greece

-Designing and conducting projects which all social groups can be addressed can be addressed to

-Take into account accessibility issues, especially for visitors with special needs

In terms of Mon - Repos Botanic Garden management and good environmental / agricultural practices:

-Focusing on good agricultural practices such as compost processes, integrated waste management)

-Reducing the use of water (use of grey water in order to irrigate plant species)

-Focusing on a realistic design program proposed by specialists based on an extensive research of the landmark to support the process of decision making

As concerns staff and local authorities' issues:

-Botanic garden employees should be well trained in order to deal with the increasing needs of the garden.

-The garden should be operated by a collective body in order to change today's practices. The museum is operated by Ministry of Culture and the garden by Municipality of Corfu.

As concerns ESD sector:

-Developing ESD programs and training local stakeholders so that they will adjust good practices in their everyday life

-Promoting experiential and participatory learning for youth and kids

-Focusing on evaluating processes before, during and after a program, receiving feedback and know - how for future steps and improvement

\subsection{SWOT Analysis}

According to the objectives and conditions which we presented above a need of a SWOT analysis will clarify and define the priority axis for the development and establishment of Mon - Repos Botanic Garden. Our SWOT analysis it is based on the premise that an effective strategy will have a positive effect on the establishment of Mon - Repos Botanic Garden and on the other hand will minimize the existence of weaknesses and threats from external causes (Ghazinoory et al., 2011).

Strengths

-An external area which combines botanical and archeological features.

-Ideal landmark to visit both in winter and summer period.

-Corfu is a famous tourism destination and the visitation of the garden is ensured. 
-The garden has an extended visiting hours schedule, especially during summer season.

-Locals in regular basis are using the garden as a recreation area

-The operation of Palaiopolis Museum considered as an advantage, the existence of two cultural organizations at the same area will increase the reputation of the area

-The existence of the open air theater in order to host multiple cultural events, conferences etc.

-Easy access by car and also using public transportation. It is worth to mention that the bus passes by Mon - Repos every twenty minutes and there is also a bus stop called Mon - Repos

Weaknesses

-Weak publicity of the garden in Municipality's official web-page. The museum it is well promoted but as regards the garden there is only one simple description

-Lack of human capital well trained in landscaping processes.

-Touring at minor pathways is difficult for visitor with special needs

-Lack of informative signs on main and minor pathways

-Increased planting needs in several areas where the plant material has been degenerated, avoiding landscapes alteration

-Weak cooperation of local authorities in order to promote the area and motivate locals participating in public discussion for Mon - Repos

Opportunities

-Lack of similar organization in local level

-Awareness that school units conduct educational programs that could take place in Mon - Repos

-High potential for the development of research projects conducted by local and national universities and technological educational institutes

-Development of low cost landscape design workshops

-Creation of an interactive website and mobilize available networks using internet

-Promote garden's cultural value and environmental value equally

Threats

-Need of a collective body concerning garden's development.

-Financial imbalance

-Need of a design team for the development of a multidisciplinary area assessment -feasibility study-

Our two year's plan concerning the above SWOT analysis can lead us to the proposal of five pillars of strategic management. These pillars include:

Pillar 1: Evaluation and design of Mon - Repos Botanic Garden

Pillar 2: Evaluation of the existence structural units

Pillar 3: Develop an active dialogue with local community, promoting the idea

Pillar 4: Develop cooperation activities between local research institutions in local and national level

Pillar 5: Make efforts to raise financial resources to ensure sustainability and prosperity of the Botanic Garden

\section{Towards Mon-Repos Botanic Garden sustainability and prosperity: Ideas and proposals}

The success of our study as described above will have to face a lot of challenges in order to be accomplished. The cooperation between public sector and stakeholders will be the key issue point for the realization of our vision. For this reason we emphasized on a realistic approach so that first steps will be easily taken, having as a result a successful start.

The realization of the Botanic Garden can be supported by the establishment of o project management structure. This team will be responsible for the design and pre-operations processes. A multidisciplinary team consisted of archeologists, agriculturalists, museologists, landscape architects, biologists etc. will support these processes. Municipality's of Corfu and Ministry of Culture evolve to the project must encourage the process giving solutions throughout the entire development process. Furthermore, the participation in research processes can be supported by 
Ionian University scientific capacity. Especially, the Department of Archives, Library Science and Museology and Department of Audio and Visual Arts can support scientific research related to archival, museological aspect as also as the production of digital products that would promote innovative tools in environmental and cultural enhancement of the area.

In order to elaborate this further, the creation of an interactive webpage will be essential and useful by locals and tourists too. The absence of this tool has raised questions about the area decreasing tourism visitation. Before, all so we propose an official webpage called Friends of Mon - Repos which will include the history, gardens, archeological interest spots and the vision concerning the area. Also, the webpage will host the whole procedure from the vision to the realization of our proposed project. A service of small digital strolls around the garden will also open up new opportunities giving the choice of discovering the area before visiting it. The creation of this specific digital service considered to be a necessity providing new modes of engagement in touring experiences (Lewi et al., 2014).

Beyond the aforementioned proposals triggering locals awareness will have a positive impact on social behavior concerning education towards environmental education (Williams et al., 2015). Having as a priority issue the participation and diffusion of every step in local community will lead to a contributory approach, bringing the project closer to the society (Grodach, 2009). The active participation of the local community should be supported firstly by low-budget actions that will awake feelings of pride and ownership of the area (Neal, 2015). A combination of an open dialogue -forum- in garden's webpage, organized visits by giving enough motivation, minimizes failure possibility at this sector.

Furthermore, the development of a work-away travelers' network would have o positive effect towards gardens promotion but also will contribute to an integrated approach as concerns gardens development and prosperity. This action could be implemented as soon as the suitable platform (through official webpage) is completed. Researchers and volunteers from all over the world will have the opportunity to work in different fields helping the design team capture the goals and expectations of the botanic garden project. Also, due to the fact that such initiatives are very common abroad we suppose that should be positively implemented in our case too. Cultural and environmental models, know-how experience will be exchanged promoting an integrated cooperation model that will assist on balancing areas prosperity (human capital) and tourism prospect as well.

Based on the above, the establishment of Mon - Repos Botanic Garden will contribute towards an integrated approach on environmental, cultural planning sector. Heritage tourism prospect will be boosted by making the first steps on project's development. Our proposal will effectively contribute to expand the role of Botanical Gardens teaching appreciation of the value of cultural and environmental sites in favor of environmental preservation and sustainability's prospect.

\section{Conclusions}

This paper highlighted the development of Mon - Repos Botanic Garden focusing on the role it can play in preservation, management and promotion of historic areas. Mon - Repos estate consists of an area flourished by archeological remains combing lush vegetation and an increased cultural value expressed by the existence of Palaiopolis Museum. Today, the emerge need of the establishment of the botanic garden in the estate is crucial. The need of environmental awareness and tourism promotion of the area will contribute to a successful future in order to achieve sustainability and further development. Local contributors in cooperation with local community as also as a design team should be responsible and should have a vision of setting out the plan of within the botanic garden will be established, defining key roles and participation processes. Towards this end, the paper addresses the existing situation presenting a SWOT analysis which leads to the five pillars of strategic management process. Through this process a number of ideas have been occurred such as the creation of a project management team, the development of Friends of Mon - Repos platform, which includes digital products such as garden digital strolls. Moreover, a work-away traveler's network will assist and positively affect the tourism dimension of the project, exchanging cultural and environmental knowledge, scientific know-how attracting visitors and contributors from all over the world.

\section{References}

1. Baika, K. Corcyra (Corfu). In: Blackman, D., Rankov, B., Baika, K., Gerding, H., Pakkanen, J., editors. Shipsheds of the Ancient Mediterranean. Cambridge University Press, Cambridge, 2014. p. 319-334.

2. BGCI. International Agenda for Botanic Gardens in Conservation, 2nd ed., Gardens Conservation International, Richmond, UK, 2012. https://www.bgci.org/files/Worldwide/News/SeptDec12/international_agenda web.pdf

3. Europe 2020. A Strategy for smart, sustainable and inclusive growth COM 2010, 2020 Final, Eur-Lex Access to European Union Law, 10 April 2017, http://eur-lex.europa.eu/legal-content/EN/TXT/PDF/?uri=CELEX:52010DC2020\&from=EN

4. Ghazinoory, S., Abdi, M., \& Azadegan-Mehr, M. "SWOT methodology: a state-of-the-art review for the past, a framework for the future". Journal of business economics and management, 2011, 12.1, 24-48.

5. Gibson, L. “\{Preservation Glossary\} Today's Word: Heritage Tourism.” National Trust for Historic Preservation, 17 June 2015, https://savingplaces.org/stories/preservation-glossary-todays-word-heritage-tourism\#.WT55R-vyjIU, Accessed 23 Apr. 2017. 
Alexandra-Aikaterini Andrianou, Georgios Papaioannou/ The Academic Research Community Publication

6. Gratzfeld, J., From Idea to Realisation - BGCI's Manual on Planning, Developing and Managing Botanic Gardens, edited by Joachim Gratzfeld, Botanic Gardens Conservation International, 2016. https://www.bgci.org/files/BG_Manual2017/BGCI\%20Manual.pdf

7. Grodach, C. "Art spaces, public space, and the link to community development." Community Development Journal, $2009,45.4,474-493$.

8. Jacques, D. “The rise of cultural landscapes ”, International Journal of Heritage Studies, 1. 2, 1995, 91-101.

9. Jiang, B., Zhang, T., \& Sullivan, W. C. "Healthy cities: mechanisms and research questions regarding the impacts of urban green landscapes on public health and well-being", Landscape Architecture Frontiers, 2015, 3.1, 24-36.

10. Knapp, A. B. and Ashmore, W. Archaeological landscapes: Constructed, conceptualized, ideational. In: Ashmore, W., and Knapp, A. B., editors. Archaeologies of Landscape, Oxford: Blackwell, 1999. p. 1-30.

11. Lewi, H., Saniga, A., \& Smith, W. "Immersive and temporal experiences in historic landscapes: designing a mobile digital guide for the Royal Botanic Gardens Melbourne”. Landscape Review, 2014 15.1, 4-23.

12. Manrique, C.,Jamal, T., \& Warden, R. Heritage Tourism and Conservation. In: Murar M., Jamal T., editors. Tourism Research Paradigms: Critical and Emergent Knowledges (Tourism Social Science Series, vol. 22). Emerald Group Publishing Limited, 2016. p. 17-33.

13. Neal, C. Heritage and participation. The Palgrave Handbook of Contemporary Heritage Research, 2015, 346-365.

14. Selman P. "Community participation in the planning and management of cultural landscapes", Journal of environmental planning and management, 2004, 47.3, 365-392.

15. Waterton, E., Watson S., eds. Heritage and Community Engagement: Collaboration or Contestation? Routledge, 2013.

16. Williams, S.J., Jones, J. P., Gibbons, J. M., \& Clubbe, C. "Botanic gardens can positively influence visitors' environmental attitudes." Biodiversity and conservation, 2015, 24.7, 1609-1620.

17. Zernioti, D. Mon - Repos antiquities, the residence, the garden. Corfu: apostrofos. 2002. \{in Greek\}. 